\title{
LOS LIBROS SENTIMENTALES DE LOS SIGLOS XV Y XVI: SOBRE LA CUESTIÓN DEL GÉNERO
}

\author{
Jesús Gómez \\ Universidad Autónoma de Madrid
}

Como se sabe, fue Marcelino Menéndez Pelayo quien acuñó el marbete de "novela sentimental» o "erótico-sentimental» en sus Origenes de la novela ${ }^{1}$, aunque allí sólo se refiere a 14 de las 21 obras citadas por Keith Whinnom en su bibliografia crítica ${ }^{2}$, ya que algunas de estas obras no eran entonces conocidas; por ejemplo, el anónimo Tratado de amores, editado recientemente por Carmen Parrilla ${ }^{3}$, o la anónima Coronación de la señora

Vol. 1 de la NBAE, Madrid, Bailly-Baillière, 1905.

The Spanish Sentimental Romance (1440?-1550). A Critical Bibliography. London, Grant and Cutler, 1983. Como punto de partida, acepto el orden y el número de obras establecido por Keith Whinnom: 1) Juan Rodríguez del Padrón: Siervo libre de Amor, 2) Fernando de la Torre: Tratado e despido a una dama de religión, 3) Don Pedro de Portugal: Sátira de felice e infelice vida, 4) Anónimo: Triste deleitación, 5) Diego de San Pedro: Arnalte y Lucenda, 6) Diego de San Pedro: Cárcel de Amor, 7) Juan de Flores: Triunfo de Amor, 8) Juan de Flores: Grisel y Mirabella, 9) Juan de Flores: Grimalte y Gradisa, 10) Lucena: Repetición de amores, 11) Nicolás Núñez: Cárcel de Amor, 12) Anónimo: Tratado de amores, 13) Anónimo: La coronación de la señora Gracisla. 14) Anónimo: Cuestión de Amor, 15) Pedro Manuel Jiménez de Urrea: Penitencia de Amor, 16) Comendador Escrivà: Queja ante el dios de Amor, 17) Anónimo: Carlas y coplas para requerir nuevos amores, 18) P. Luis Escrivá: Veneris tribunal, 19) Juan de Cardona: Tratado llamado Notable de Amor, 20) Juan de Segura: Proceso de cartas de amores, 21) Juan de Segura: Queja y aviso contra Amor. Para una primera actualización, aunque parcial, de la bibliografia crítica de Keith Whinnom, véase mi artículo "La aportación española al estudio de la ficción sentimental, 1980-1989: tendencias y posibilidades», La Corónica (en prensa).

${ }^{3}$ "El Tratado de amores, nuevo relato sentimental del siglo XV", $A F E, 2,1985,473-486$. De Carmen Parrilla véase también: “El Tratado de amores en la narrativa sentimental», $B B M P$. 64. 1988, 109-128. 
Gracisla, o la Triste deleitación ${ }^{4}$. Ahora bien, lo más discutible del planteamiento de Menéndez Pelayo es que sólo atiende al contenido. Casi por definición, la novela sentimental sería cualquier historia de amor. Desde esta perspectiva, las dudas de Carmelo Samoná sobre la existencia de un género sentimental están absolutamente justificadas. En oposición a la supuesta homogeneidad temática descubierta por Menéndez Pelayo, Samoná pone el acento sobre la ueterogenea indole strutturale delle varie operette» ${ }^{5}$. Todavía no se ha resuelto la antinomia planteada por Samoná hace ya treinta años. Es cierto que la caracterización temática de Menéndez Pelayo no es suficientemente precisa, pero nadie ha sido capaz de reducir la mencionada «heterogeneidad estructural» del género a un mínimo común denominador. De manera inevitable, ello ha originado un cierto escepticismo entre la crítica con respecto a esta cuestión, escepticismo que está implícito también en la citada bibliografia de Keith Whinnom.

Como no parece haber límites genéricos precisos, Whinnom sólo tiene en cuenta el criterio histórico e incluye todas las historias de amor de corta extensión escritas y/o publicadas entre la segunda mitad del siglo XV y la primera mitad del siglo XVI: «including all the short, or comparatively short, love-stories composed in Spain between 1440? and 1550" ${ }^{6}$. Sabiendo incluso que, entre estas obras, hay varias que sólo de manera marginal se pueden considerar como sentimentales, por ejemplo, el Triunfo de Amor de Juan de Flores ${ }^{7}$ o la anónima Coronación de la señora Gracisla. Aunque Whinnom no da más detalles, podemos suponer que las dudas sobre la inclusión de estas obras vienen originadas porque en ellas no hay una historia amorosa personal desarrollada suficientemente en términos novelescos: el núcleo de La coronación consiste en la descripción de unas fiestas cortesanas, y el del Triunfo en un debate alegórico entre el dios de Amor y sus servidores. Por las mismas razones, sin embargo, también se podría discutir la pertenencia al género sentimental de otras obras que incluye Keith Whinnom, como el Tratado de Fernando de la Torre, las anónimas Cartas y coplas para requerir nuevos amores o la Repetición de amores de Lucena, donde sólo hay una breve historia amorosa, pero plagiada de la Historia de Enea Silvio Piccolomini ${ }^{8}$.

4 La Triste deleitación ha sido editada por E. Michael Gerli, Washington, Georgetown University Press, 1982, y por Regula Rohland de Langbehn, Morón, Argentina, Universidad, 1983). En cuanto a la Coronación de la señora Gracisla, véase la edición de Keith Whinnom, en Dos opúsculos isabelinos. Exeter, University of Exeter, 1979.

Studi sul romanzo sentimentale e cortese nella letteratura spagnola del Quattrocento. Roma, Carucci, 1960, p. 34.

- The Spanish Sentimental Romance. p. 5.

'Véase Patricia E. Grieve, «Juan de Flores' Other Work: Technique and Genre of Triumpho de Amom, JHP, 5, 1980-1981, 25-40; y la edición de Antonio Gargano Pisa: Giardini, 1981.

"Véase mi comunicación "Literatura paraescolar y difusión del humanismo en el siglo xv: 
Así pues, la nómina de The Spanish Sentimental Romance es discutible desde un punto de vista genérico. No hay ninguna homogeneidad formal entre las obras citadas, sino una serie de procedimientos entre los que se pueden diferenciar al menos estos cinco: 1) la mezcla de prosa y verso o prosimetrum, 2) la alegoría, 3) la autobiografia, 4) la epístola y 5) el debate o altercatio. No obstante, se ha subrayado sobre todo la presencia de las autobiografias y de las epístolas, olvidando las otras formas literarias citadas quizá porque se ha pretendido estudiar el género sentimental tan sólo desde el desarrollo posterior de la novela, a partir del Romanticismo. Sin embargo, la autobiografia o la epistola son procedimientos sentimentales tan característicos como los otros que después han caído en desuso: el prosimetrum, la alegoria y la altercatio.

Por ejemplo, el prosimetrum no sólo aparece en los primeros libros sentimentales, como el Siervo libre de Amor, la Sátira de felice e infelice vida o la Triste deleitación, sino que también está presente en las últimas obras del género, editadas durante el siglo XVI, como la Queja de Escrivá, la anónima Cuestión de Amor o la Queja y aviso contra Amor. Lo mismo sucede con la alegoría, que es un elemento constante en los primeros libros sentimentales, de manera especial en el Siervo libre de Amor y en la Sátira de felice e infelice vida, pero que no ha desaparecido tampoco de las últimas obras, como las ya citadas o el Veneris tribunal, editado en 1537.

No hay evolución lineal desde el prosimetrum o la alegoría hacia otros procedimientos narrativos más modernos, como la epístola o la autobiografia. De hecho, la primera y la única novela propiamente epistolar es el Proceso de cartas de amores (Toledo, 1548) de Juan de Segura, ya que las anónimas Cartas y coplas para requerir nuevos amores (¿1515?) tan sólo son un manual epistolar'. No es que el Proceso de Segura carezca de antecedentes en el uso de las epístolas amorosas, incluso en otros libros sentimentales, como los de Diego de San Pedro ${ }^{10}$, lo que sucede es que el Proceso supone un cambio cualitativo con respecto a las obras anteriores. Como

la Repetición de amores de Lucena", en Actas del III Congreso Internacional de la Asociación Hispánica de Literatura Medieval (Salamanca, 3-6 octubre, 1989) (en prensa).

$\checkmark$ Véase la edición facsímil de F. López Estrada, "Un pliego de Cartas y coplas para requerir nuevos amores, 1535», en Revista de Bibliografia Nacional, 6, 1945, 227-239. Aunque no se conserva, parece que la primera edición de esta obra es de 1515 , según F. J. Norton: $A$ Descriptive Catalogue of Printing in Spain and Portugal (1501-1520). Cambridge, University Press, 1978.

${ }_{10}$ Véase el artículo de Françoise Vigier: "Fiction épistolaire et novela sentimental en Espagne aux $\mathrm{XV}^{*}$ et $\mathrm{XVI}^{*}$ siècles», Mélanges de la Casa de Velázquez, 20, 1984, 229-259. Sobre la tradición de las cartas de amores, véase Domingo Ynduráin: «Las cartas de amores», en Homenaje a Eugenio Asensio, Madrid: Gredos, 1989, 487-495, y María Carmen Marin Pina: "Las cartas de amor caballerescas como modelos epistolares", en La Réception du texte littéraire, ed. Jean-Pierre Etienvre y L. Romero. Zaragoza, Universidad de Zaragoza-Casa de Velázquez, 1988, pp. I I-24. 
dice Domingo Ynduráin: «Respecto a las obras anteriores, no hay sólo un cambio cuantitativo (más o menos cartas), sino una alteración cualitativa tanto frente a las narraciones esmaltadas de cartas como a las series de epístolas en verso" ${ }^{11}$.

En cuanto a la autobiografia, tampoco es un elemento constante en los libros sentimentales. Ya en el Siervo libre de Amor, Juan Rodriguez del Padrón alterna la primera persona gramatical con la tercera, cuando narra la "Estoria de dos amadores». Lo mismo sucede en la Triste deleitación, donde el Enamorado comienza hablando en primera persona y, sin embargo, después de la extensa disputa entre la Razón y la Voluntad, las aventuras sentimentales del Enamorado son contadas en tercera persona. La primera persona no vuelve aparecer hasta el viaje alegórico en verso que cierra el libro. También hay otros libros sentimentales escritos enteramente en tercera persona, como el Grisel y Mirabella, el Tratado llamado Notable de Amor, la Cuestión de Amor o la Queja y aviso contra Amor.

Además, hay que tener en cuenta que una narración no tiene que ser necesariamente autobiográfica por el simple hecho de estar escrita en primera persona. Así, en las obras de Diego de San Pedro, escritas en primera persona, hay una clara separación entre las funciones del narrador y el mundo de la aventura sentimental: en Arnalte y Lucenda, Arnalte le refiere su pasado al autor que transmite la historia oída a las damas de la Reina Católica. En la Cárcel de Amor, en cambio, el autor relata por sí mismo la historia de Leriano, en la que desempeña un papel decisivo, pero distingue con toda claridad su labor como autor-narrador de su actuación como tercero en los amores entre Leriano y Laureola ${ }^{12}$. Así pues, las dos obras de Diego de San Pedro sólo son autobiográficas en el sentido de que están escritas en primera persona, y no porque exista una identificación entre las experiencias del autor y las del protagonista, al menos gramaticalmente. Como afirmación general, no se puede sostener que los libros sentimentales sean un género autobiográfico ${ }^{13}$.

" "Sobre el Proceso de cartas de amores (Venecia, 1553) de Juan de Segura", en Philologica Hispaniensia in honorem $M$. Alvar. Madrid, Gredos, 1985, p. 186. Y Javier Huerta Calvo: "Tradición y modernidad en la novela sentimental: el ejemplo de Juan de Segura", en España, teatro y mujeres. Estudios dedicados a Henk Oostendorp, ed. M. Gosman y H. Hermans. Amsterdam/Atlanta, Rodopi, 1989, pp. 207-215.

12 Se ha estudiado mucho este aspecto de la Cárcel de Amor. Véase, por ejemplo, Peter N. Dunn: "Narrator as Character in the Cárcel de Amor", $M L N, 94,1979,187-199$; Alfonso Rey: "La primera persona narrativa en Diego de San Pedro", BHS, 58, 1981, 95-102; Esther Tórrego: "Convención retórica y ficción narrativa: el caso de Cárcel de Amor», $N R F H, 32,1983$, 330-339; James Mandrell: "Author and Authority in Cárcel de Amor: the Role of El Auctor", $J H P, 8,1984,99-122$.

13 Otra cosa son las relaciones entre la autobiografia y el análisis psicológico de los personajes, como ha puesto de relieve Maria Eugenia Lacarra: «Sobre la cuestión de la autobiografia en la ficción sentimental», en Actas del l Congreso de la Asociación Hispánica de Lite- 
Otro ejemplo formal que adquiere gran importancia en la caracterización de los libros sentimentales y que, sin embargo, apenas ha sido estudiado es el debate o altercatio. Pensemos en los debates alegóricos entre las distintas potencias del alma que aparecen en el Siervo libre de Amor, en la Sátira de felice e infelice vida o en la Triste deleitación. Pensemos también en los dubbi y questioni d'amore que aparecen en un conocido episodio del Filócolo, de Boccaccio ${ }^{14}$ que fue traducido al castellano por Diego López de Ayala y editado de manera independiente en varias ocasiones durante el siglo XVI. Además, Alfonso de Ulloa incluye la traducción de Diego López de Ayala al final de la Cuestión de Amor, a partir de la edición veneciana de 1553. De hecho, el tema central de la anónima Cuestión de amor deriva de la segunda cuestión del Filócolo. Se trata de saber quién sufre más: el amante rechazado por su dama o el amante correspondido, pero cuya amada ha muerto. En cambio, el tema central del Veneris tribunal de Escrivá deriva de la cuestión once del Filócolo.

Un debate central en los libros sentimentales es el que enfrenta a misóginos y profeministas ${ }^{15}$. Este debate aparece de manera explícita en la Cárcel de Amor y, sobre todo, en el Grisel y Mirabella de Juan de Flores. Ahora bien, en conjunto, la importancia que adquiere el debate sentimental está en relación con la importancia que adquieren otros modos de expresión como la autobiografía o las cartas, formas todas de la primera persona gramatical que establecen una relación directa entre los interlocutores $o$, lo que es más importante, entre éstos y el lector. Los libros sentimentales son una sucesión de discursos oratorios en el más amplio sentido de la palabra, y ello se refleja claramente en el punto de vista que adoptan estos libros, donde tiende a desaparecer el narrador omnisciente, que es sustituido por la presentación directa de los acontecimientos, característica de lo que Norman Friedman llamaba "the Dramatic Mode» ${ }^{16}$.

De hecho, se podría establecer una pequeña casuística en los libros sen-

ratura Medieval, ed. V. Beltrán, Barcelona, PPU, 1988, pp. 359-368. No hay por qué pensar que el «yo sentimental» es un yo autobiográfico cuando la obra está escrita en primera persona. Puede ser un yo ejemplar que representa un carácter genérico, lo que no es infrecuente en la Edad Media. Véase L. Spitzer, "Note on the Poetic and the Empirical 'I' in Medieval Authors", Traditio, 4, 1946, 414-422.

14 Véase P. Rajna: «L'episodio delle questioni d'amore nel Filocolo del Boccaccio», Romania, 31, 1902, 28-81.

is La bibliografía sobre el tema es muy amplia. Véase tan sólo Jacob Ornstein: «La misoginia y el profeminismo en la literatura castellana», $R F H, 3,1941,219-232$; Elena Gascón Vera: «La ambigüedad en el concepto del amor y de la mujer en la prosa castellana del siglo $\mathrm{xV}$ », BRAE, 59, 1979, 119-155; Anthony van Beysterveldt: «Los debates feministas del siglo XV y las novelas de Juan de Flores», Hispania, 64, 1981, I-13.

16 "Point of View in Fiction: The Development of a Critical Concept", PMLA, 70, 1955, 1162-1184. Véase Alan D. Deyermond, «El punto de vista narrativo en la ficción sentimental», en Actas del I Congreso de la Asociación Hispánica de Literatura Medieval, pp. 359-368. 
timentales para documentar esta ausencia de la figura del narrador omnisciente. Así, en un primer grupo de obras, el narrador desaparece por completo, como sucede en la Penitencia de Urrea, escrita enteramente en diálogos y cartas, o en las dos obra epistolares citadas: las anónimas Cartas y coplas y el Proceso de Segura. En un segundo grupo, el narrador omnisciente desaparece sustituido por la primera persona gramatical, que se puede identificar o no con el autor de la obra, como hemos visto. Se identifica con el autor en el Siervo, en la Sátira del Condestable, en el Tratado de amores, en la Queja ante el dios de Amor, en el Veneris tribunal o en Grimalte $y$ Gradisa. Pero no sucede asi en la Cárcel de Amor ni en Arnalte y Lucenda. Finalmente, en un tercer grupo: el de los relatos sentimentales escritos en tercera persona (Triste deleitación, Grisel y Mirabella, la Cuestión de Amor, el Tratado llamado Notable de Amor o la Queja y aviso contra Amor), la narración también es secundaria y sólo sirve para unir los discursos retóricos de los protagonistas: epístolas, diálogos, poesías y oraciones retóricas de todo tipo. Así, por ejemplo, en la Queja y aviso contra Amor, la narración en tercera persona está interrumpida constantemente por las quejas de Lucíndaro ante el dios de Amor, desarrolladas en extensos apóstrofes.

La acción y, por consiguiente, la narración sólo existe en los libros que estudiamos cuando sirve como pretexto para la expresión directa de los sentimientos. Los protagonistas sentimentales no actúan, salvo en contadas excepciones. Por lo general, son seres pasivos que escriben cartas y poesías, se lamentan en largos apóstrofes o incluso discuten con sus rivales, pero casi nunca combaten fisicamente con ellos. Es cierto, por ejemplo, que Leriano derrota a Persio y rescata a su amada manu militari, o que Arnalte mata a Elierso, su falso amigo, o que Grisel derrota a todos los caballeros del reino de Escocia antes de conseguir a Mirabella. Pero todos estos episodios son excepcionales y están tratados de manera sumaria. Como dice Arnalte: "porque la prolixidad en las tales cosas más enojosa que agradable sea, no quiero nuestro trance por extenso decir». O como dice el autor de la Cárcel: "Finalmente, por no detenerme en esto que parece cuento de historias viejas...." ${ }^{17}$.

Es muy significativo, en este sentido, que Grimalte fracase en la empresa de conquistar a su amada porque no puede convencer a Pánfilo de que ame a Fiometa. Es, por tanto, un fracaso dialéctico y no bélico el que determina su historia amorosa, como sucede también en la Cárcel de Amor. El duelo militar tiene menos importancia que el altercatio puramente verbal, porque el proceso erótico de conquista es de carácter retórico y oratorio, ya que se basa en la elocuencia. De este modo, el caballero andante se transforma, si

"Véase Harvey L. Sharrer, "La fusión de la novela artúrica y sentimental a fines de la Edad Media", $A F E, 1,1984,147-157$, y E. Spinelli: "Chivalry and its Terminology in the Spanish Sentimental Romance», La Corónica, 12, 1983-1984, 241-253. 
puedo decirlo así, en un caballero parlante: una suerte de homo loquax que prefigura el cortigiano renacentista. El cambio se puede relacionar con la nueva importancia que adquieren las letras o el saber en la formulación del viejo tópico de las armas y las letras. Pero también se puede relacionar con la nueva concepción cuatrocentista de la retórica ${ }^{18}$.

Hay una gran presencia de elementos retóricos en los libros sentimentales, tanto en el estilo como en las formas literarias mayores. Keith Whinnom ha estudiado con provecho los elementos retóricos de la Cárcel de $A m o r^{19}$, aunque el análisis se podría extender sin duda a las otras obras del género. No es este mi propósito, sin embargo. Me basta con subrayar el carácter retórico de las grandes unidades formales que aparecen habitualmente en estos libros. Así, el debate o altercatio entre dos interlocutores se puede relacionar con el genus iudiciale, donde se decide lo iustum/iniustum de la quaestio ${ }^{20}$. A su vez, el proceso de cartas de amores se puede relacionar con la oratio suasoria y disuasoria ${ }^{21}$, ya que el amante intenta convencer a la amada de la pureza de sus deseos, mientras que ésta se niega por la pureza de su honra. Es un debate, por tanto, en torno a lo honestum. En fin, el lamento funerario o planctus depende del genus demonstrativum y panegírico $^{22}$. Hay varios ejemplos, como el lamento de la madre de Leriano en la Cárcel de Amor, o el lamento de Felisel por Flamiano en la Cuestión de Amor.

En resumen, las unidades literarias de los libros sentimentales se pueden relacionar con los tres genera retóricos: judicial, deliberativo y demostrativo. El modo de composición de estas unidades también está codificado retóricamente, según las partes en las que se subdivide la oratio. Y, además, el propio proceso de seducción sentimental es de carácter retórico porque se basa en la elocuencia, como señalaba Ovidio ${ }^{23}$.

Lo importante es que la presencia de los elementos retóricos citados afecta y, en cierto modo, determina la propia naturaleza del proceso de seducción sentimental, que se configura así como un ars amatoria o "arte de amores». Se trata de establecer un grado erótico intermedio entre el amor

18 Véase ahora el artículo de Jeremy N. H. Lawrance, "On Fifteenth-Century Spanish Vernacular Humanism", en Medieval and Renaissance Studies in honour of $R$. B. Tate, ed. 1 . Michael y R. A. Cardwell, Oxford, Dolphin Books, 1986, pp. 63-87.

${ }_{19}$ Véase Keith Whinnom, introd. a su ed., Cárcel de Amor de Diego de San Pedro, en Obras completas, vol. 2. Madrid, Castalia, 1972, pp. 44-66, y «Diego de San Pedro`s Stylistic Reform", BHS, 37, 1960, 1-15.

${ }_{20}$ Véase Heinrich Lausberg: Manual de retórica literaria, trad. José Pérez Riesco. Madrid, Gredos, 1966, 61 y ss.

${ }_{21}$ Ibid., $\$ 229$ y ss.

"I Ibid., $\$ 238$ y ss.

23 Ars amatoria, ed. José-Ignacio Ciruelo. Barcelona, Bosch, 1987, lib. I, vv. 457-460: «Disce bonas artes, moneo, Romana iuventus, / Non tantum trepidos ut tueare reos; / Quam populus iudexque gravis lectusque senatus, / Tam dabit eloquio victa puella manus." 
ferino y el divino. Aceptar la existencia de este grado intermedio es más importante que discutir sobre su verdadera naturaleza o sobre su denominación, sea ésta la de "amor cortés» o la de "amor cortesano». Claro está que el amor de los libros sentimentales se basa en el servicio continuo del amante a su amada, pero éste no es un servicio desinteresado o puramente espiritual, sino que tiene por objeto la posesión fisica.

La constancia amorosa es una convención cortesana típica, pero también una forma retórica de galanteo. Los amantes recurren a la concepción cortés del amor para justificar su deseo sexual, como sucede en los cancioneros, y para lograr que las damas les correspondan. Ya dice Segura, en su Queja y aviso contra Amor, que Amor "mandó pregonar en sus cartas muchas leyes, entre las cuales fue una que el que bien amase que le fuese dado por premio favor de su señora ${ }^{24}$. Según esto, parece que las mujeres están obligadas a satisfacer de una o de otra manera los deseos de sus pretendientes, siempre que éstos se comporten como amadores perfectos. Probablemente ésta es una de las razones por las que escribe Nicolás Núñez una continuación de la Cárcel de Amor donde Laureola se muestra arrepentida de su comportamiento con Leriano ${ }^{25}$. La superioridad de la dama o de la amada no es más que aparente, un tópico poético para halagar la vanidad femenina de las mujeres.

Conviene insistir en la estrecha relación que se establece entre la lectura y la educación sentimental femenina en los propios libros sentimentales, muchos de los cuales están dedicados a mujeres concretas que mayormente pertenecen a la nobleza cortesana. Por ejemplo, la anónima Cuestión de Amor está dedicada a Bona Sforza, hija de Isabel de Aragón, y la Sátira está dedicada a la hermana del Condestable, Isabel de Portugal. Diego de San Pedro dedica el Arnalte a las damas de Isabel la Católica. Urrea dedica la Penitencia a su madre, la condesa de Aranda. Cardona dedica su Tratado a doña Potenciana de Moncada. Lucena dedica la Repetición de amores a su amiga, lo mismo que Juan de Flores cuando escribe el Grisel y Mirabella o el Grimalte y Gradisa.

La influencia del público femenino se puede observar también en el argumento de los libros sentimentales. Juan de Cardona, por ejemplo, escribe su Tratado porque doña Potenciana de Moncada «ha oýdo dezir, que los más hombres que tratan de amores, después de ganada la voluntad de la dama, se rresfrían y se dexan y buscan pequeñas causas para to hazer; o otros que, visto que las damas a quien sirben se entretienen en sus honrras, luego que a poco tiempo no consiguen el provecho de su Intençión; se de-

${ }^{24}$ Edición de Joaquin del Val, Sociedad de Bibliófilos Españoles. Madrid, 1956. p. 84.

$2 s$ Véase Keith Whinnom: «Nicolás Núñez's Continuation of the Cárcel de Amor (Burgos, 1496)", en Studies in Spanish Literature of the Golden Age Presented to Edward M. Wilson, ed. R. O. Jones. London, Tamesis, 1973, pp. 357-366. 
gustan y dan de mano a los amores» ${ }^{26}$. El perfil del héroe sentimental está determinado por las expectativas del público femenino y, por este motivo, Cardona retrata a un amante tan constante que es capaz de ser mártir por amor, como Leriano. Así, le demuestra a doña Potenciana de Moncada que todavía hay amantes tan perfectos «como se lee aver avido en los tiempos pasados" ${ }^{27}$. Obsérvese, de paso, la estrecha relación que se establece entre la lectura y la educación sentimental femenina. Lo mismo sucede en Grimalte y Gradisa de Juan de Flores, pero esta vez ya en el propio argumento del libro. Gradisa ha leído la Fiammetta de Boccaccio y está preocupada por la inconstancia amorosa de los hombres. Flores, Grimalte en la ficción, escribe su obra para demostrar justamente lo contrario ${ }^{28}$.

$\mathrm{Al}$ referirse a las obras del género sentimental, Samonà ${ }^{29}$ señala que son «il frutto di un'epoca di profonda trasformazione del gusto». Sin duda, esta profunda transformación del gusto tiene que ver con la importancia que adquiere en la Baja Edad Media un nuevo público de carácter laico y cortesano, como ha estudiado para el caso español Jeremy N. H. Lawrance ${ }^{30}$. De las necesidades literarias de este público y de sus condiciones ideológicas depende el sentido último de los libros sentimentales o, más generalmente, de las "artes de amores», por utilizar otra vez la expresión de Urrea en el prólogo a su Penitencia de Amor: "Esta arte de amores está ya muy vsada en esta manera por cartas y por çenas que dize el Terencio»" ${ }^{31}$.

En realidad, tenemos dos posibilidades cuando estudiamos los libros sentimentales. Una primera consiste en establecer un modelo formal estricto con respecto al cual definir el resto de las obras analizadas. Ya sabemos cuáles son los problemas de esta primera posibilidad: no hay un solo modelo formal dentro de las obras que cataloga Keith Whinnom en The Spanish Sentimental Romance, sino que coexisten varios y también varias tradiciones literarias: desde la oratio académica, en el caso de Lucena, hasta le epistola autobiográfica, pasando por la comedia celestinesca, en el caso de la $\mathrm{Pe}$ nitencia de Amor. La diversidad de tradiciones literarias está relacionada con aquella «heterogeneidad formal» de la que nos hablaba Carmelo Samonà y que, como hemos visto, es hasta cierto punto irreductible; los procedimientos examinados (prosimetrum, alegorias, autobiografias, epistolas y debates) se suceden en un ars combinatoria muy variada.

${ }^{26}$ Edición de Juan Fernández Giménez. Madrid, Eds. Alcalá, 1982, pp. 65-66.

27 Ibid., p. 65.

${ }^{28}$ Véase Barbara F. Weissberger: «Authors, Characters and Readers in Grimalte y Gradissa), en Creation and Re-creation: Experiments in Literary Form in Early Modern Spain, ed. Ronald E. Surtz y Nora Weinerth. Newark, Delaware, Juan de la Cuesta, 1983, pp. 61-77.

${ }^{29}$ Carmelo Samonà, p. 54.

30 «The Spread of Lay Literacy in Late Medieval Castile», BHS, 62, 1985, 79-94.

${ }^{31}$ Edición de R. Roulché-Delbosc, vol. X de la Bibliotheca Hispanica, Barcelona-Madrid, L'Avenç, 1902, p. 3. 
Una segunda posibilidad consiste en considerar el estudio de los libros sentimentales formando parte de esas «artes de amores» a las que aludía Urrea. En las "artes de amores» confluyen varias tradiciones literarias que vienen de la Antigüedad y de la Edad Media: Ovidio, el De Amore del capellán Andrés o la comedia elegíaca, entre otros ejemplos. Además, en estas "artes de amores" no hay un modelo formal estricto, por lo que se podrían incluir todos los libros catalogados por Keith Whinnom y también otros afines, como el Tratado de cómo al hombre es necesario amar atribuido al Tostado ${ }^{32}$, el Tratado de amor atribuido a Mena ${ }^{33}$, o la Celestina, donde las «artes de amores» están presentes aunque sólo sea como referente paródico ${ }^{34}$. El problema de este planteamiento es que las «artes de amores» no son un género literario, sino una actitud ideológica, como señala Domingo Ynduráin ${ }^{35}$. Claro que esta actitud ideológica nos puede servir para explicar un aspecto central de los libros sentimentales que hasta ahora no ha sido suficientemente destacado. Me refiero a su naturaleza polémica.

En un libro reciente, Amor y pedagogia en la Edad Media, Pedro M. Cátedra señala que en el género sentimental, o «al menos en algunos de sus especímenes, como el Siervo libre de Amor», se advierte «la opción por una actitud polémica en contra de las concepciones naturalistas del amor (...) para acogerse a una concepción propiamente cortés y poética» ${ }^{36}$. El autor ejemplifica esta opción con el caso del Siervo libre de Amor frente al Tratado de cómo al hombre es necesario amar. Se podría ir todavía más lejos en este razonamiento, para añadir que los libros sentimentales no sólo nacen (en el caso de Rodriguez del Padrón) en contra de las concepciones naturalistas del amor, sino que incluso, en el propio desarrollo del género, se reproduce la misma dialéctica ideológica cuando aparece la Celestina que, utilizando la retórica de las "artes de amores», pretende destruir sus presupuestos ideológicos. Lo mismo sucede en la Repetición de amores, donde no por casualidad la presencia del Tostado es determinante.

Después de la Celestina surgen otras obras donde, desde el esquema formal celestinesco, se intenta ofrecer una contrarréplica a las críticas de Rojas con respecto a las «artes de amores», como sucede en la Penitencia

3 Del Tostado sobre el Amor, ed. Pedro M. Cátedra. Barcelona, "Stelle dell'Orsa», 1986.

13 Edición de Maria Luz Gutiérrez Araus. Madrid: Eds. Alcalá, 1975.

* Véase Edwin J. Webber: "The Celestina as an arte de amores», MPh, 55, 1958, 145-154; Doroty S. Severin: «La parodia del amor cortés en La Celestina», Edad de Oro, 3, 1984, 275281; Domingo Ynduráin: "Un aspecto de La Celestina», en Estudios sobre el Siglo de Oro. Homenaje a Francisco Ynduráin, Madrid, Editora Nacional, 1984, pp. 521-540; María Eugenia Lacarra: «La parodia de la ficción sentimental en la Celestina», Celestinesca, 13, 1989, 11-29.

35 "Un aspecto...", p. 523.

36 Amor y pedagogia en la Edad Media. Salamanca, Universidad, 1989, p. 144. 
de Amor. De este modo, podemos distinguir al menos tres fases ${ }^{37}$ en el desarrollo dialéctico o polémico de los libros sentimentales: una primera, en el caso del Siervo libre de Amor, donde se ataca la concepción naturalista del amor. Una segunda, en la Celestina y también en la Repetición de amores, donde se critica la concepción cortés y poética características de las «artes de amores». Y una tercera, la de la Penitencia de Amor, donde se defiende esa misma Concepción Cortés, como he estudiado en otro lugar ${ }^{38}$.

Además del desarrollo polémico, hay que tener en cuenta la presencia de una serie de rasgos que se pueden relacionar con el tratadismo del siglo XV. Y es que la "exposición erótica doctrinal» - como dice Pedro M. Cátedra- «tiene más lugar en el tratadismo amoroso del siglo XV que el mismísimo análisis de las pasiones individuales, que generalmente se ha visto como el fin básico de la novela sentimental española ${ }^{39}$. Es decir, que la teoría amorosa aparece en los libros sentimentales de manera doctrinal y polémica. De ahí la importancia que adquiere el debate en el desarrollo de la casuistica amorosa.

En otro sentido, se podría pensar que en la mayoría de los relatos sentimentales se establece también un debate ideológico entre el yo cortesano explícito en el texto, escrito muchas veces en primera persona, y el tú implícito del lector. Ya que no olvidemos que con frecuencia los libros sentimentales se conciben con un envio donde se ofrece un exemplum para cualquiera de las posibilidades del ars amatoria: para evitar el amor, por ejemplo, pero también para conseguirlo. A veces, como sucede en el Grisel y Mirabella, se trata de enfrentar un comportamiento cortesano ejemplar (el de Grisel en este caso) y otro errado (el de Torrellas), o como sucede de manera todavía más explícita en el Grimalte y Gradisa, donde se opone el comportamiento de Grimalte al de Pánfilo. Este mismo enfrentamiento polémico origina una cierta tendencia a la dualidad que se observa incluso en el agrupamiento binario de las historias sentimentales, como sucede ya en el Siervo libre de Amor, entre la historia del Siervo y la de Ardanlier y Liesa, o en el Proceso de cartas de amores con respecto a la Queja y aviso contra Amor, escrita para consolar a Juan de Segura, como dice su amigo: «para que toméys algún consuelo y exemplo para vuestro trabajo, aý os embío los amores del leal amador Luzindaro y la hermosa Melusina, que con esta

"Estas tres fases coinciden aproximadamente con las que establece Regula Rohland de Langbehn desde otro punto de vista: «Desarrollo de géneros literarios: la novela sentimental española de los siglos xv y xvim, Filologia, 31, 1986, pp. 57-76. Véase Alan D. Deyermond: "Las relaciones genéricas de la ficción sentimental española», en Symposium in honorem Martín de Riquer. Barcelona, Universidad, 1986, pp. 75-92.

38 "Las 'artes de amores', Celestina y el género literario de la Penitencia de Amor de Urrea», Celestinesca 14, 1990, 3-16.

${ }^{39}$ Amor y pedagogia, p. 157. 
obra en el griego juntos estavan con que creo gran deleyte sentiréys, y alivio muy grande para vuestro mals ${ }^{40}$.

Desde este punto de vista genérico, lo más importante son las relaciones de implicación que se producen entre la retórica sentimental y el público lector. Porque la retórica no es tan sólo una manifestación literaria, sino también una coartada ideológica que sirve para justificar la existencia de un sentimiento intermedio entre el amor ferino y el divino. Ésta sería la última lección implícita en los libros sentimentales, que se dirigen a un público en gran parte cortesano y femenino, que es lo que explica la propia existencia del género sentimental. En último extremo, esta hipótesis sobre la naturaleza polémica de los libros sentimentales nos llevaria a la concepción del género definido como un "horizonte de espera», por utilizar esta expresión de Hans-Robert Jauss en un conocido artículo sobre la teoría de los géneros en la literatura medieval ${ }^{41}$. Se trata de comprender los libros sentimentales no como genera o clases en un sentido lógico y aristotélico, sino como grupos o familias históricas.

40 Ed. cit., p. 60.

" "Littérature médiévale et théorie des genres" (trad. fr.), Poétique, 1, 1970, 79-101. 